\title{
Cultura Visual, hibridismo e a passividade da visão em tempos tecnológicos
}

\author{
Manuela Cristina Siebert (UDESC)
}

\begin{abstract}
RESUMO
Neste artigo tenho a intenção de refletir sobre os hibridismos presentes no campo da Cultura Visual, tanto nas suas relações transdisciplinares quanto no contato com a tecnologia para a veiculação e criação das imagens. A passividade da visão é colocada como uma provocação para pensar sobre a relação entre as imagens que vemos e a nossa subjetividade, objetivando compreender essas relações não apenas através de um viés cultural e social, mas considerando que existem funções inerentes do cérebro humano que participam dessa rede de significações. O artigo aponta o ensino das Artes Visuais e da Cultura Visual como importante ferramenta para a reflexão a cerca das imagens e do próprio comportamento social na contemporaneidade.
\end{abstract}

PALAVRAS-CHAVE: Cultura Visual; Hibridismo; Tecnologia; Visualidade; Ensino das Artes Visuais.

\section{ABSTRACT}

In this article I intend to reflect on the hybridisms present in the field of Visual Culture, both in its transdisciplinary relations and in the contact with technology for the placement and creation of images. The passivity of the vision is posed as a provocation to think about the relation between the images that we see and our subjectivity, aiming to understand these relations not only through a cultural and social bias, but considering that there are inherent functions of the human brain that participate in this network of meanings. The article points out the teaching of the Visual Arts and Visual Culture as an important tool for the reflection about the images and the social behavior itself in the contemporaneity.

KEYWORDS: Visual Culture; Hybridism; Technology; Visuality; Visual Arts Teaching .

Com a globalização e as revoluções industriais e tecnológicas passamos a receber passivamente uma quantidade muito maior de informações e imagens que inconscientemente passam a atuar na nossa subjetividade, desse modo a cultura Visual tornou-se um campo de discussão necessário para compreender a atuação representacional dessas informações não somente no campo das Artes Visuais, mas também no cotidiano e no comportamento social. As imagens exercem grande poder de influência e manipulação sobre as pessoas, que raramente 


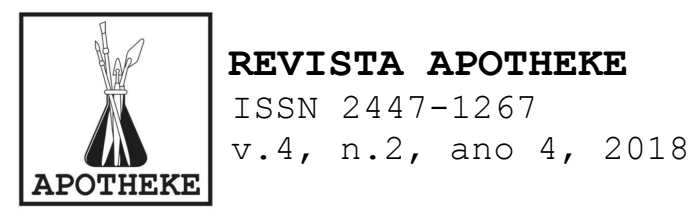

compreendem ou analisam as possíveis nocividades de seu contato com essas imagens.

Os hibridismos na Cultura Visual ocorrem a partir da perspectiva de que esse campo não é fixado em uma disciplina específica, mas que é capaz de estar presente em variados campos e disciplinas que trabalham direta ou indiretamente com a imagem e com a visão, desse modo é considerado um campo transdisciplinar ou adisciplinar conforme aponta Fernando Hernandez (2011). Além disso, o híbrido pode ser observado a partir da necessidade da Cultural Visual operar através de cruzamentos entre as imagens e os embasamentos teóricos e intelectuais sobre cultura, comportamento, cotidiano, linguagens, visualidade, e etc. Seu objetivo torna-se compreender o processo de ver e suas relações com os processos de significação tanto a nível simbólico como comunicativo.

As discussões sobre a Cultura Visual engendram variados pontos de vista considerando que seu domínio é amplo e expandido e não conta com uma limitação específica de atuação ou um estabelecimento como uma disciplina curricular fechada em si mesma, desse modo subsiste entre as fronteiras de vários outros campos e disciplinas. Willian Mitchell, professor da Universidade de Chicago e pesquisador na área dos estudos visuais, não descreve objetivamente a composição do domínio dos estudos visuais ou uma finalidade específica para tal, assim como outros teóricos que também escrevem sobre o tema. Não acredito que alguém o faça sem limitar as possibilidades de atuação dos estudos visuais, parece que as múltiplas funções e interpretações são inerentes às imagens e ao campo que busca estudá-las.

o que, afinal, compõe o domínio dos estudos visuais? Não apenas a história da arte e da estética, mas a imagem científica e técnica, o cinema, a televisão e a mídia digital; bem como investigações filosóficas em epistemologia da visão, estudos semióticos de imagens e de sinais visuais, investigação psicanalítica da pulsão 


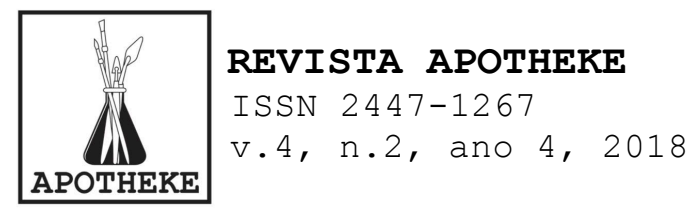

escópica; estudos fenomenológicos, fisiológicos e cognitivos do processo visual; estudos sociológicos do espectador e visualização, antropologia visual, física óptica e visão animal e assim por diante. (MITCHELL, 2001 ).

As confusões teóricas e falácias que envolvem o campo da Cultura Visual dificultam a compreensão sobre suas reais intenções, Mitchell em seu artigo "Showing Seeing, Uma crítica da Cultura Visual" aponta alguns desses mitos sobre os estudos visuais. Acredito que um dos pontos mais relevantes é compreender que os estudos visuais não colocam a imagem acima da linguagem escrita, mas entendem que a própria linguagem escrita conta também com uma projeção visual que faz parte do valor simbólico das palavras.

Atuando como designer gráfico, a partir da experiência de trabalhar com a comunicação visual, constantemente encontro teorias e procedimentos que são operados sobre as imagens a fim de induzir ou conduzir as pessoas a terem determinadas atitudes e comportamentos, e principalmente influenciar no seu consumo. Essa observação está diretamente ligada às imagens veiculadas pela mídia através de propagandas, e todo o bombardeamento que ocorre através da internet e da televisão nesses tempos tecnológicos. Em níveis mais sutis está presente nos cardápios dos restaurantes, nas roupas, nas vitrines e em basicamente todas as imagens presentes no nosso cotidiano e nas nossas relações, não excluindo os objetos culturais e artísticos. Apesar de algumas dessas influências estarem bastante claras, muitas imagens fazem isso sem que possamos perceber atuando diretamente no nosso inconsciente.

$\mathrm{Na}$ contemporaneidade os estudos sobre a Cultura Visual tornam-se importantes não somente para os estudantes de Artes Visuais, mas para a sociedade no geral. Os estudantes das áreas de artes, design, comunicação entre outras já estão mais familiarizados com a potencialidade das imagens e o poder que exercem sobre o comportamento, mas $\bigcirc$ mesmo geralmente não 


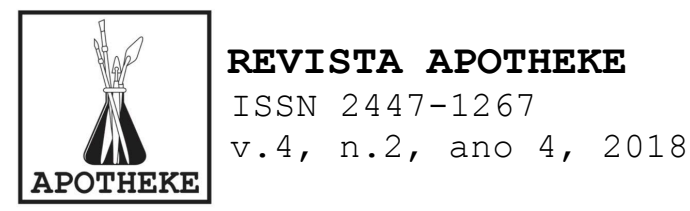

acontece com os estudantes até o nível médio, por exemplo. Desse modo o ensino das Artes Visuais e da Cultura Visual, para além dos muros da universidade, colabora diretamente com a compreensão dos alunos sobre as significações da imagem e suas construções sociais e simbólicas tanto no sentido pessoal como para o coletivo, fazendo com que o contato com a visualidade e com as imagens seja trazido para um nível mais consciente e crítico e menos passivo ou influenciado.

Entender o processo da visão vai além de compreender as imagens e suas relações culturais, vai ao encontro com a compreensão individual que cada um estabelece a partir dos seus dados e experiências sociais como um todo. Desse modo vemos que a Cultura Visual não busca interpretar uma imagem de uma maneira única, ou propor uma leitura sistematizada baseada apenas nos seus aspectos formais e estéticos, pois isso não estaria de acordo com toda a simbologia, a história, ou os aspectos culturais e sociais por trás da imagem. As possibilidades de leitura ou interpretação de uma imagem podem ser inúmeras, não somente porque existem diferenças culturais entre povos, mas porque cada indivíduo tem uma interpretação particular sobre o que vê que se baseia também nas suas experiências. O desafio dos estudos visuais não é estabelecer uma maneira apropriada de ler uma imagem, mas ampliar o conhecimento sobre si e a partir disso poder modificar os modos de ver e de compreender as imagens e como elas carregam a cultura e o comportamento social de uma geração para outra.

\section{Hibridismos na cultura visual}

Hibridismos são contaminações que ocorrem a partir de cruzamentos de diferentes elementos tendo como resultado um híbrido. Podem ocorrer a partir da mistura de linguagens, mídias, imagens, espécies ou gêneros. Considerando essa definição podemos ver algumas formas de hibridismo no campo da Cultura Visual, primeiramente porque ela opera entre 


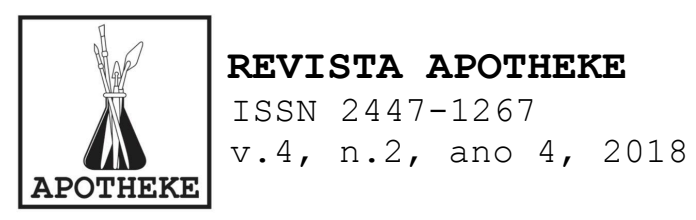

fronteiras e disciplinas não se estabelecendo como uma disciplina separada das demais. Desse modo os estudos visuais estão presentes em diversos currículos servindo como um meio de hibridizar as linguagens em que atua.

Como colocado por Fernando Hernandez (2011) apesar da possibilidade de apresentar alguns enfoques da Cultura Visual como meio de estabelecer uma didática pedagógica, esses enfoques não são fechados em si mesmos, mas se vinculam entre si e se hibridizam com outras referências e contribuições. Os hibridismos rompem com a ideia de pureza ou separação da Cultura Visual em um ambiente próprio e particular, colocando seu enfoque sobre os espaços e fronteiras articulando a interpretação sobre a visualidade das imagens.

O hibridismo também pode ser associado ao fato de a Cultura Visual não se estabelecer apenas no âmbito da compreensão da imagem pelo viés da estética, mas também atuar a partir da teoria cultural e de outras linguagens que corroboram com o sistema de significações das imagens e suas atuações políticas, históricas ou sociais. A hibridação também pode ser identificada nos processos de criação e veiculação das imagens quando utiliza de diferentes meios e tecnologias para incorporar a imagem na cultura. Em tempos tecnológicos a criação e a reprodutibilidade das imagens são realizadas facilmente através dos computadores e das mídias, por exemplo, - que amplifica a ideia de que a comunicação atual torna-se cada dia mais visual.

O híbrido conta um caráter contaminado e impuro, do mesmo modo a Cultura Visual atua em um não lugar, em um vazio, ou entre fronteiras de disciplinas, portanto trata-se de um campo igualmente impuro e contaminado que atua sem distinção em áreas variadas e democraticamente estabelece relações entre meios e experiências anteriormente não relacionados. A Cultura Visual também está em constante contato com as imagens híbridas que combinam diferentes tecnologias tendo em vista 


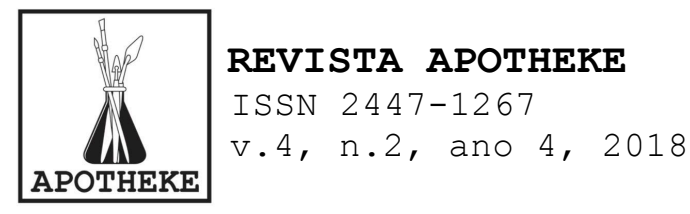

que na contemporaneidade essas imagens são bastante frequentes tanto na criação artística quanto na publicidade.

\section{Passividade da visão e atividade do ato de ver}

Para entender as relações entre as imagens e a cultura torna-se necessário compreender antes como nosso cérebro processa e interpreta as imagens. Não podemos considerar que vemos uma realidade, mas vemos a partir da mente traduzindo às imagens em códigos que estão ou não de acordo com o que cremos. A visão pode ser entendida como um sentido passivo, pois muitas vezes as imagens podem ser visualizadas e retidas no inconsciente sem propriamente serem percebidas por nós conscientemente. Desse modo a visão configura uma porta de fácil acesso para a comunicação e principalmente para a manipulação das massas. O cérebro é quem realmente interpreta as imagens e cria os diálogos entre o que vemos e o que a mente compreende, desse modo podemos entender que a passividade da visão está ligada ao seu próprio mecanismo e que a atividade deve ser operada a partir de um nível mental.

Concordo com a colocação de Mitchell quando ele diz que a Cultura Visual ou as imagens não são os únicos meios de manipulação política ou social, porém atualmente com a facilidade na difusão das imagens elas tornaram-se um canal bastante importante para essas ações. Cabe a nós trazermos essas informações para o nível consciente a fim de compreender como essas imagens são carregadas de valores simbólicos que inevitavelmente se comunicam conosco, e essa comunicação não manipula somente o nosso comportamento, mas o comportamento e os nossos modos de ver também manipulam as imagens que vemos ao nosso redor. Existe um diálogo entre o que vemos e o que nos vê.

Se observarmos atentamente as imagens que invadem nossas redes sociais ou até mesmo a televisão, poderemos perceber que as imagens geralmente são repetidas, e isso ocorre também como 


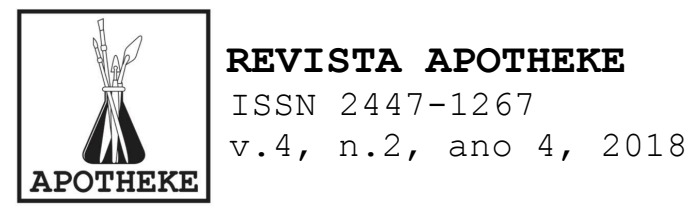

uma resposta ao nosso diálogo com elas. Quanto mais interagimos com determinadas imagens, mais imagens semelhantes surgem, e a construção do olhar e da imagem vão alimentando umas as outras. É nesse ponto de troca que as imagens podem ser utilizadas a fim de influenciar ou manipular interações, comportamentos e próprio consumo.

A passividade da visão ocorre porque inevitavelmente vemos, estamos sujeitos a imagens que não necessariamente optamos conscientemente por ver desde o nosso nascimento. A atividade do ato de ver estaria voltada para a intenção de olhar as imagens de um modo mais crítico e menos automático ou passivo. Essa atividade estaria ligada primeiramente a compreensão do indivíduo sobre si mesmo e sobre seu próprio sistema de crenças a fim de poder estabelecer um contato mais consciente com as imagens que o cercam conseguindo discernir o valor simbólico das imagens que recebe passivamente.

Compreendendo que a televisão exerce grande poder de influência sobre as massas, por exemplo, assistir passivamente os seus programas ou comerciais influencia escolhas e até mesmo comportamentos sociais que muitas vezes não estão de acordo com as próprias crenças particulares do indivíduo, mas que estão diretamente conectadas com um inconsciente coletivo que está atuando também no nível cultural. A atividade no ato de ver a televisão, por exemplo, ampliaria a compreensão do indivíduo sobre as intenções e simbologias das imagens apresentadas trazendo as mesmas para um nível de reflexão mais consciente.

A televisão foi utilizada apenas para fins de exemplificação da passividade no nosso olhar nos tempos tecnológicos, mas o mesmo ocorre com a internet e com tudo que vemos a nossa volta. Essa passividade da visão e a possibilidade de ver mais ativamente como um modo de obter um olhar mais crítico para as imagens, está presente em todas as 


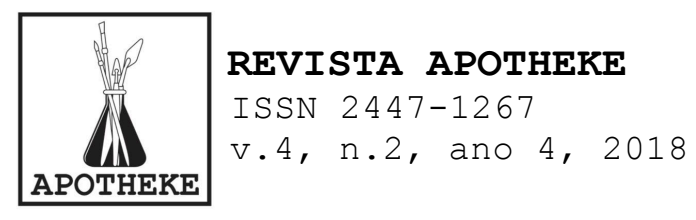

nossas relações tanto com as imagens midiáticas, os ambientes ou as pessoas que nos relacionamos.

Em um nível inconsciente as nossas escolhas estão sujeitas ao nosso sistema de crenças que está diretamente ligado com a visualização repetida das mesmas imagens como um meio de reforçar o que acreditamos. Um exemplo disso é a cultura de violência estabelecida na nossa sociedade. A maior parte da população acredita que o país está violento e que essa violência só aumenta dia após dia. As imagens que recebemos diariamente através da internet ou da televisão reforçam essa crença através da repetição, e cada vez mais a crença se estabelece no nosso sistema. Passamos a ver violência em tudo, em todas as atitudes, justamente porque cremos que não existe bondade ou mal entendido, apenas violência e ódio. Isso faz com que a população, mesmo aqueles que não se consideram violentos, ajam inconscientemente com violência.

Portanto além de compreender o sistema de crenças pessoal, tentar estabelecer um entendimento sobre as crenças culturalmente estabelecidas torna-se importante para compreender as imagens que vemos e os reais motivos para sua criação ou repetição nas mídias. A partir dessa observação, podemos entender mais facilmente como se relacionar com as imagens de forma mais crítica e consciente, e assim consequentemente criar imagens que possibilitem um maior nível de reflexão dos espectadores.

\footnotetext{
Por que algumas imagens são tão facilmente compreendidas e o seu rápido reconhecimento é tão apaziguador? Por que outras imagens provocam tanto impacto, tanta emoção (energia/afeto) e tanto tumulto interno? Em nossa sociedade, a repetição, a facilitação do percurso já realizado e o apaziguamento provocado pela identificação daquilo que já é conhecido, que já foi experimentado, sustentam a manutenção de nossas crenças, de nossos "clichês" culturais. (DUARTE, 2012).
}

Os tempos tecnológicos onde a difusão das imagens torna-se facilitada e universalizada, a partir da televisão, cinema, 


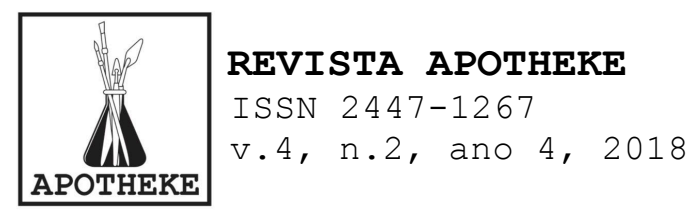

fotografia, ou internet, a passividade da visão fica ainda mais evidente. A partir do design pude vivenciar a experiência de criar imagens ou produtos que trabalham a partir de um conhecimento cultural e social para influenciar nas escolhas das pessoas. Esses conhecimentos influenciam as criações de todos os elementos de marketing e divulgação, desde as embalagens dos produtos do supermercado até as roupas dos atores de um filme ou novela.

No campo do design e da comunicação visual existem vários exemplos de como essas influências são estabelecidas a partir de estudos psicológicos e comportamentais. Um exemplo são as cores utilizadas nos ambientes dos restaurantes e lanchonetes, por exemplo. Geralmente são escolhidas cores como o vermelho, - laranja ou amarelo, pois o contato visual com essas cores eleva os níveis de agitação e ansiedade e fazem com que as pessoas tenham atitudes compulsivas. Em culturas menos ansiosas ou violentas, como o Japão, por exemplo, essas estratégias visuais não atingem as pessoas da mesma forma como acontecem no Brasil.

\footnotetext{
Se nossa experiência visual não pode ser identificada como uma janela transparente para o real, em função das diferentes práticas e variantes culturais, logo não pode ser compreendida como uma experiência natural/ universal no sentido de que seja igual para todos independente do contexto histórico. (SÉRVIO, 2014).
}

Acredito que a Cultura Visual esteja interessada nessa possibilidade de atividade no ato de ver, convertendo a passividade da visão em uma escolha por refletir e criticar o que nos é apresentado a fim de estabelecer relações simbólicas, históricas, culturais, sociais e até mesmo políticas com o ambiente que nos cerca e com as imagens que chegam até nós. o exemplo do Japão, uma sociedade culturalmente baseada em valores de autoconhecimento, autocontrole e meditação, reforça a ideia de que uma das 


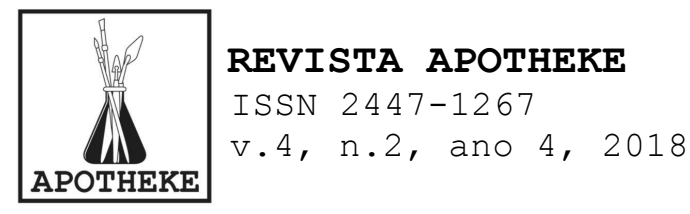

partes mais imprescindíveis para uma maior atividade do ato de ver está pautada no conhecimento pessoal e na compreensão de si mesmo.

\section{Ensino e cultura visual}

Considerando que a Cultura Visual exerce esse espaço de cruzamento, contaminação e reflexão sobre as imagens, acessando além da visualidade o seu caráter social e cultural, podemos entender que ela pode exercer um importante papel na interpretação visual e na crítica sobre o caráter simbólico e iconográfico das imagens. Desse modo exerce um importante papel quando incorporada no ensino das Artes a fim de ressignificar nossas relações com os objetos artísticos, e com as imagens que nos cercam diariamente.

A compreensão dos níveis sociais, políticos, culturais ou históricos por trás da criação ou divulgação das imagens apresenta aos alunos uma maior possibilidade de compreensão tanto das imagens e objetos artísticos como objetos do cotidiano. Os artistas por sua vez já operam através dessas relações e reflexões buscando, em algumas situações, adequar suas imagens à visão da massa a fim de se inserirem no mercado da arte comercializando seus objetos, ou com o intuito de atingir um maior número de pessoas. Como aponta Fernando Hernandez (2011), a Cultura Visual atua na educação como um modo de deslocar o olhar e tentar ver além do que a visão pode captar, buscando relações e possíveis conjunturas que são inerentes das imagens tanto artísticas quanto cotidianas. Desse modo o autor coloca como principal objetivo da Cultura Visual a mudança de foco do olhar e do lugar de quem vê.

A discussão sobre as imagens, e sua constituição para além do que vemos, torna-se imprescindível para a compreensão das suas relações com as nossas escolhas, comportamentos sociais, e objetos culturais. Promovem um deslocamento do olhar para além das representações ampliando o campo de reflexão dos 


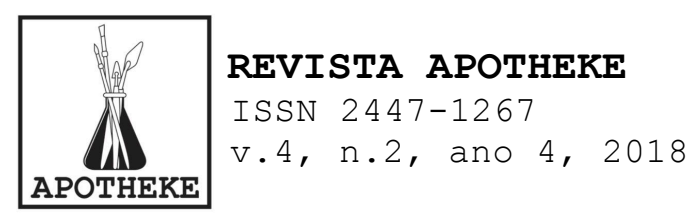

alunos e facilitando também sua compreensão sobre a Arte. o deslocamento do olhar permite novas interpretações sobre as imagens, porém também permite novas interpretações sobre o próprio posicionamento e lugar do aluno dentro de todos esses aspectos culturais, históricos e sociais, estabelecendo relações entre as imagens apresentadas e seu próprio modo de se apresentar ao mundo.

\begin{abstract}
Penso que ensinar Artes Visuais requer propiciar ao aluno um conjunto de saberes que lhe permita encontrar uma realidade interna, a sua realidade interna, ali onde ela se esconde e se revela, para além do clichê. Não é no simples, no corriqueiro, no imediato, no ligeiro, ou nas superfícies da imagem que a arte (e a humanidade que ela suporta) se revela. É no mais complexo, mais denso, mais hermético, mais profundo e, como diz Barthes, no mais exato "é isso!". (DUARTE, 2012).
\end{abstract}

A Cultura Visual juntamente com o ensino das Artes Visuais na escola pode exercer a função de estabelecer novas relações não somente com as imagens, mas com os modos de ver e refletir sobre os mais diversos assuntos. As questões de estereótipo fortemente ancoradas nas imagens e baseados em construções sociais, históricas e culturais podem ser discutidas a partir de um olhar crítico sobre as imagens midiáticas que reforçam esses padrões estabelecidos questionando, por exemplo, quais as intenções ou vantagens em reforçar essas ideias ou quais as possibilidades de mudarmos nosso olhar para descontruir imagens, que apesar de socialmente ou culturalmente aceitas, exercem opressão ou uma forma violência silenciosa.

Uma das funções da Arte sempre foi problematizar e convidar os espectadores às reflexões, o esforço mental e a complexidade da arte nos deslocam e nos forçam a estabelecer um posicionamento crítico com relação ao mundo que nos cerca. O mesmo pode ser feito através da Cultura Visual no ensino das Artes Visuais fora do âmbito acadêmico, fazendo com que os alunos possam exercer também essa função do artista de problematizar questões, de estabelecer um olhar contemplativo 


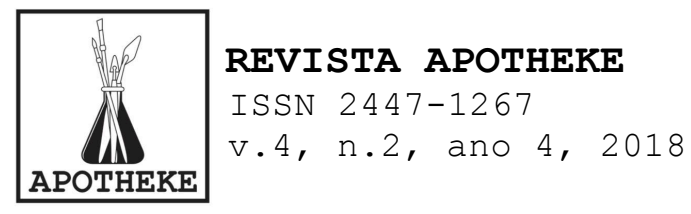

e sensível, mas igualmente crítico e consciente. Essa ideia ainda estaria além de possibilitar ao aluno essas novas relações com o mundo simplesmente como um espectador, mas iria ao encontro com problematizar também suas relações como criador de imagens.

Em tempos tecnológicos a difusão de fotografias e vídeos tornou-se muito mais fácil e rápida, além de estar mais disponível para população no geral. Em uma turma de sexto ano grande parte dos alunos tem celular e câmeras fotográficas, o que nos permite compreender que além de se relacionar com as imagens, eles também criam e compartilham imagens. A importância de exercer um ato de ver mais consciente e ativo, mais crítico e ciente das influências que as imagens exercem no nosso comportamento social, influencia diretamente na criação das suas próprias imagens.

Portanto, se o que vemos também nos vê, a partir do momento que cada um busca compreender como é visto, o que vê também é alterado. A mudança no modo como vemos as imagens deve começar a partir do desejo único e pessoal de cada um e das suas intenções em modificar seus sistemas de crenças que agem automaticamente determinando os comportamentos ou modos de ver. Essas mudanças podem ser incentivadas através da educação e de um estudo sério sobre a Cultura Visual. Trata-se de um trabalho complexo e por vezes desconfortável, tendo em vista que trabalha muitas vezes confrontando suas próprias ideias já estabelecidas, mas que pode ser feito a partir do momento que a própria sociedade compreende sua necessidade e importância.

\section{Conclusões}

Concluo que a Cultura Visual não se estabelece em um espaço limitado e definido, e que de acordo com os autores apresentados qualquer ideia de classificação pode ser perigosa ou exercer uma função reducionista ao termo. O estudo sobre a 


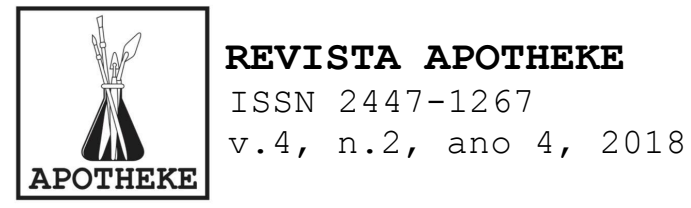

Cultura Visual pode ser utilizada a partir de diversas perspectivas e incorporada nas mais variadas áreas que fazem o uso direto ou indireto da imagem. Sua atuação vai além de analisar uma imagem esteticamente, mas lança reflexões sobre as imagens e seus contextos históricos, culturais, sociais, políticos, e suas ligações com outras linguagens. Os hibridismos na Cultura Visual reforçam sua adisciplinaridade ou transdisciplinaridade, tendo em vista que seu caráter hibrido apresenta características de contaminação e impureza, de cruzamentos entre disciplinas, meios, gêneros, espécies, entre outros.

A importância do ensino da Cultural Visual juntamente com - ensino das Artes Visuais no âmbito escolar está ligada a necessidade de refletir conscientemente e exercer um modo de ver mais crítico sobre as imagens. Em tempos tecnológicos em que o contato com as imagens é cada vez maior, torna-se necessário que tenhamos um maior entendimento das relações que elas estabelecem entre o nosso comportamento e a nossa compreensão sobre a cultura, a política e o comportamento social entre outros aspectos.

A percepção das imagens, e as relações que estabelecemos com elas, influenciam diretamente na percepção sobre nós mesmos, portando torna-se imprescindível buscarmos um modo mais crítico de contato a fim de nos posicionarmos de modo mais consciente e positivo no mundo. As reflexões e a mudança de foco do nosso olhar podem nos colocar contra algumas crenças coletivas das quais nos apropriamos automaticamente fazendo com que mudemos definitivamente nossa relação com as imagens, e a partir disso podemos criar imagens que dialogam primeiramente com o nosso mundo interno não se condicionando às imagens externas. O resultado seria uma mudança de comportamento e dos modos de se relacionar com as imagens e com o mundo ao nosso redor, consequentemente surgiria um modo 


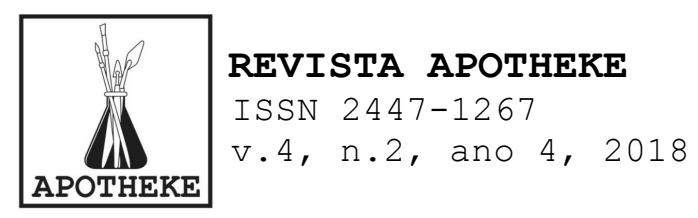

mais consciente de criar imagens a fim de colaborar ou não com as ideias divulgadas e reforçadas pela mídia e pelas massas.

\section{REFERÊNCIAS}

DUARTE, Maria Lúcia Batezat. Cultura Visual, Neurociência e diferentes discursos: entretenimento, publicidade, jornalismo e arte. Artigo apresentado na Anpap, 2012.

HERNANDEZ, Fernando. A cultura visual como um convite à deslocalização do olhar in MARTINS, Raimundo; TOURINHO, Irene (Org.). Educação da Cultura Visual: conceitos e contextos. Santa Maria: Editora UFSM, 2011, p. 31 - 49.

MITCHELL, W.J.T. Showing Seeing: Uma crítica da Cultura Visual. Artigo apresentado na conferência sobre História da Arte, Estética e Estudos Visuais realizada no Clark Institut em 2001, publicado em: "Journal of Visual Culture" vol. 1, no.2, 2002. p.165.181.

SÉRVIO, Pablo Petit Passos. O que estudam os estudos de cultura visual? Santa Maria: Revista Digital do LAV, 2014. Vol.7, n.2, p.196-215.

Disponível em: http://dx.doi.org/10.5902/1983734812393.

\section{Manuela Cristina Siebert}

http://lattes.cnpq.br/8034379456669172

Mestranda do curso de Pós Graduação em Artes Visuais da Universidade do Estado de Santa Catarina na linha de pesquisa de Ensino das Artes Visuais.

Artigo apresentado como requisito parcial do Seminário Especial: Arte e Cultura Visual, ministrado pela Prof. ${ }^{a}$ Dr. ${ }^{a}$ Aline Nunes. 